\title{
Sinonasal Undifferentiated Carcinoma: A Rare Entity
}

\author{
Mohamed Dhaha ${ }^{1}$, Sawssen Dhambri ${ }^{2}$, Souheil Jbali ${ }^{3}$, Makram Tibini ${ }^{4}$, Slim Touati ${ }^{5}$, Skander Kedous ${ }^{6}$, Said Gritli ${ }^{7}$
}

\begin{abstract}
Malignant tumors of sinonasal tract are rare, representing only $3 \%$ of head and neck cancers. Sinonasal undifferentiated carcinoma (SNUC) is a rare entity recently described by Frierson et al. in 1986. Many clinical and pathological aspects of this disease remain misunderstood. We report the case of 52-year-old male suffering from a rapidly fatal SNUC of the right nasal cavity. We tried to focus on the clinical and histological presentations of the disease, and we discussed the different possible treatment modalities, which are still guided by small retrospective studies. SNUC is a rare entity. Its management is challenging due to its local aggressive behavior and high propensity to metastasis. There is no evidence that aggressive therapy offers better survival. A better comprehension of the disease is necessary.

Keywords: Chemoradiation, Immunohistochemestry, Malignant tumor, Sinonasal tract, Surgery.

Clinical Rhinology An International Journal (2019): 10.5005/jp-journals-10013-1354
\end{abstract}

\section{INTRODUCTION}

Malignant tumors of sinonasal tract are rare, representing less than $1 \%$ of all cancers and $3 \%$ of all upper aerodigestive tract cancers. ${ }^{1}$ Sinonasal undifferentiated carcinoma (SNUC) is a relatively rare entity specific to the nasal cavities and paranasal sinus. According to the World Health Organization, SNUC is defined as a highly aggressive and clinicopathologically distinct carcinoma of uncertain histogenesis composed of pleomorphic tumor cells with frequent necrosis and should be differentiated from other carcinomas or olfactory neuroblastoma. SNUC usually presents with vague symptoms, such as nasal obstruction, headache, and epistaxis for a short duration. ${ }^{2}$ Therefore $70-100 \%$ of tumors are T4 at presentation. ${ }^{3,4}$ Since it was first described by Frierson et al. in $1986,{ }^{5}$ few cases of SNUC were reported; thus, management of these tumors is still unclear and guided by small series with small number of patients. ${ }^{4,6}$ Long-term survival rates are deceiving reaching $50 \%$ in the best cases. ${ }^{\text {? }}$

\section{Case Description}

In June 2014, a 52-year-old painter sought medical consultation in Salah Azaez Oncology Institute, Department of Head and Neck Surgery, with unilateral epistaxis as chief complaint. Cluster pain of the right hemi-face and ipsilateral recent swelling were also reported. The patient was a heavy smoker, and only a benign prostatic hypertrophy in medical history has been noted. Clinical examination showed a right $2-\mathrm{cm}$ paranasal swelling erasing the nasolabial fold, hypoesthesia in the right V2 territory, and an ipsilateral 2-cm cervical lymph node in the level II. Endoscopy found a fungating white formation filling the right nasal cavity. Computed tomography (CT) scan of the facial massif concluded a tissular process in the right nasal cavity respecting the floor and the palatine vault with a little invasion of the adjacent medial wall of the orbit. Two biopsies have been performed under local anesthesia. Histological examination coupled with immunohistochemistry (IHC) concluded SNUC with (PS100-, cytokératine +, EMA+). Magnetic resonance imaging (MRI) showed a tissular process of right nasal cavity and the ethmoïd with hyposignal in $\mathrm{T} 1$ and hypersignal in T2 with gadolinium enhancement (Figs 1 and 2). Chest CT scan showed a suspicious pulmonary node. The patient was classified
1-5,7Department of Head and Neck Surgey, Salah Azaez Oncology Institute, Tunis, Tunisia

${ }^{6}$ Salah Azaez Oncology Institute, Tunis, Tunisia

Corresponding Author: Mohamed Dhaha, Department of Head and Neck Surgey, Salah Azaez Oncology Institute, Tunis, Tunisia, Phone: +21692764 278, e-mail: dhaha.mohamed87@gmail.com

How to cite this article: Dhaha M, Dhambri S, Jbali S, et al. Sinonasal Undifferentiated Carcinoma: A Rare Entity. Clin Rhinol An Int J 2019; 12(1):21-23.

Source of support: Nil

Conflict of interest: None

T3N1M1 following the UICC TNM Classification 2009, $7^{\text {th }}$ edition. Three cycles of 5FU-CDDP chemotherapy were administrated to the patient. Evolution was marked by rapid growth of the facial swelling complicated with blindness in an interval of 2 months. Flash irradiation in an analgesic purpose was administrated. The patient died after several months after a cataclysmic bleeding.

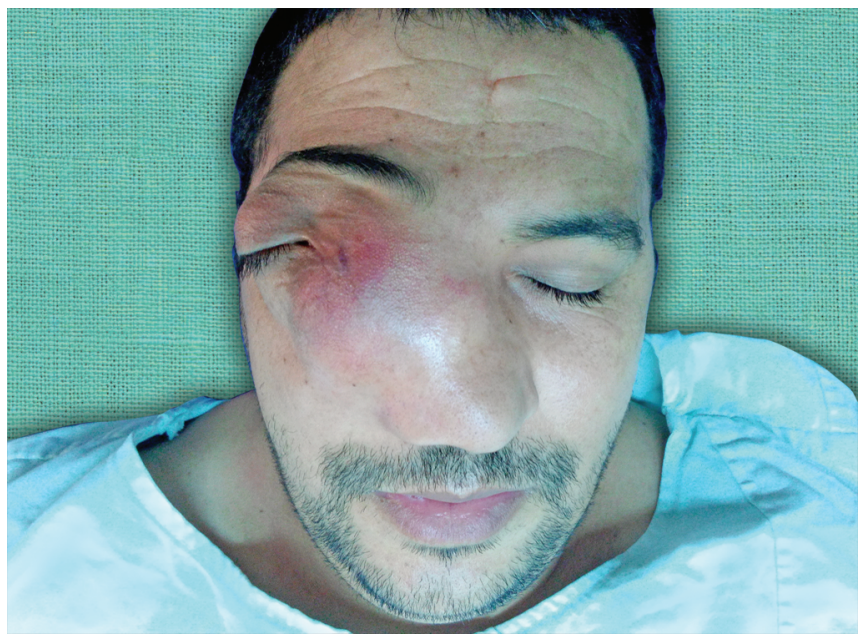

Fig. 1: Clinical evolution 2 months after diagnoses showing a massive swelling deforming the face

o The Author(s). 2019 Open Access This article is distributed under the terms of the Creative Commons Attribution 4.0 International License (https://creativecommons. org/licenses/by-nc/4.0/), which permits unrestricted use, distribution, and non-commercial reproduction in any medium, provided you give appropriate credit to the original author(s) and the source, provide a link to the Creative Commons license, and indicate if changes were made. The Creative Commons Public Domain Dedication waiver (http://creativecommons.org/publicdomain/zero/1.0/) applies to the data made available in this article, unless otherwise stated. 


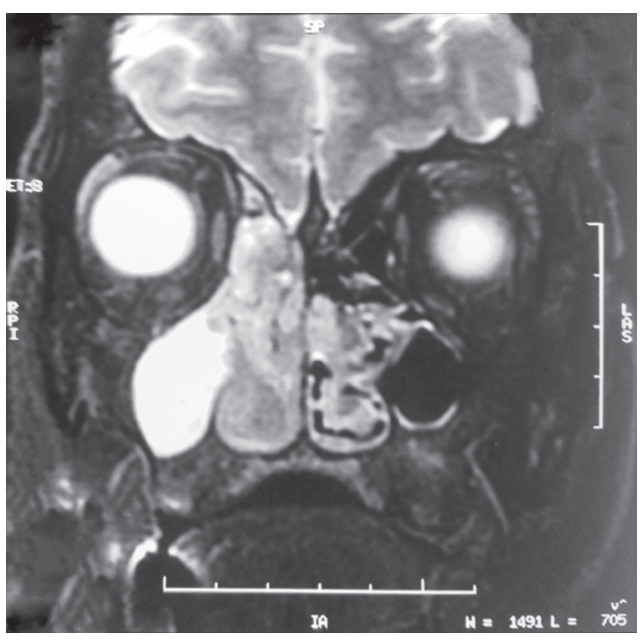

Fig. 2: T2-gadolinium-enhanced MRI coronal section showing a nasal right process infiltrating the ethmoid with retention image in the ipsilateral maxillary sinus

\section{Discussion}

In 1986, Frierson et al. reported the first SNUC series, including eight patients all with advanced disease with orbital and cranial extension, all were treated with chemoradiation therapy. Only three patients were alive after 1 year. ${ }^{5}$ Since then, fewer than 200 cases were reported in the literature. ${ }^{4,6}$ Recently, Kuo et al. reported 435 cases in a multicenter American review. ${ }^{8}$ This is to our knowledge the largest cohort ever reported. Worthy improvements in the management of SNUC were achieved, but many clinical and therapeutic features are still unclear. In addition to its uncertain histogenesis, the etiology of SNUC is to date unknown. The role of cigarette smoking and previous radiation therapy was not demonstrated. Unlike undifferentiated nasopharyngeal carcinoma (UCNT), it seems that there is no correlation between SNUC and Epstein Barr virus (EBV). ${ }^{9}$

Males are more affected by the disease than females, with broad age range. ${ }^{9}$ According to Kuo et al., there was more males with a sex ratio near to 1.7, age range between 18 years and 85 years, and half of patient were younger than 55 years. ${ }^{8}$

For a short duration, symptoms are vague, such as nasal obstruction epistaxis and headache. Therefore, $70-100 \%$ are staged T4 at presentation, and $10-30 \%$ had metastatic cervical lymph nodes. ${ }^{3,4}$ According to an American review by Caroline $C$ Xu et al., headache and neurologic symptoms are present in $45 \%$ of cases and epistaxis in $25 \% .{ }^{10}$ The same review reports $42.3 \%$ of patient had orbital involvement at diagnosis. ${ }^{10}$ In our case, cluster trigeminal pain, headache, and epistaxis, concomitant to the paranasal swelling, were present at the first consultation with a cervical node metastasis. A distant metastasis in the lung was identified which classifies the patient as stage IV according to the TNM classification.

Histological examination coupled with $\mathrm{IHC}$ is necessary for the diagnosis, and it must be performed by an experienced pathologist. The light microscope features of the SNUC include the presence of a hypercellular proliferation with different growth patterns, including trabecular, lobular, sheet-like, and organoid patterns. ${ }^{11,12}$ Mitotic index is high with important necrosis and vascular emboli. There is no glandular or squamous differentiation. ${ }^{11,12} \mathrm{IHC}$ is necessary for the diagnosis. The immunostaining for the cytokeratine 7, 8, and 19 and the $\mathrm{EMA}+{ }^{2,13}$ like in our case, is documented in the literature.

Imaging is fundamental in dealing with malignant tumor of sinonasal tract. While CT scan is very contributive in highlighting bone destruction, MRI is interesting in studying extension to soft part. ${ }^{14,15}$ Tumor limits visible in CT scan are correlated in only $78 \%$ of cases to surgical and histological findings. ${ }^{16}$ These correlations reach $94 \%$ with MRI and $98.4 \%$ with gadolinium-enhanced MRI. ${ }^{16}$ Imaging is necessary in diagnosis, staging, and follow-up.

According to Kuo et al., SNUC is difficult to treat for many reasons including, advanced stage at presentation, proximity to critical structures, and rarity. ${ }^{8}$ No ideal treatment strategy has been systematically evaluated due to the small number of reported cases. Most authors recommend an aggressive therapy to eradicate the diseased tissues. ${ }^{8,17,18}$ Surgery, when possible, is indicated. It consists usually of mutilating craniofacial resection with maxillectomy, orbital exenteration, and occasionally neurosurgical involvement. Neoadjuvant chemotherapy associating cyclophosphamide, doxorubicin, and Vincristine, followed by surgical resection and postoperative or preoperative radiotherapy, is the most common regimen described in the literature. ${ }^{3,6,19}$ According to Musy et al., these tumors are no longer surgical if one or many of the following structures are involved: cavernous sinus, infratemporal fossa, the brain, or the orbital cone bottom. ${ }^{6}$ Systematic irradiation of the cervical lymph node compartments for N0 patients is recommended by some authors due to the disease aggressiveness. ${ }^{4,6}$ The 5 -year survival rates are low. According to Kuo et al., the cumulative 5-year survival rate was $41.5 \%{ }^{8}$ Close survival rates were found in other series. ${ }^{10,17}$ Surgery associated with chemotherapy or chemoradiation therapy is correlated with the best survival rates in univariate and multivariate analysis according to the same authors. No chemotherapy regimen has been selected as specific to in the management of the SNUC. Docetaxel + 5-fluorouracil (5-FU) + cisplatin (TPF), cysplatine + 5-FU (PF), cysplatine + Taxotere, and cisplatine alone were used. ${ }^{17}$ In our case, a palliative chemotherapy was administrated to the patient due to the distant pulmonary metastasis.

\section{CONCLUSION}

SNUC is a rare tumor of sinonasal tract with uncertain histogenesis. It remains challenging due to its aggressive local behavior and its high propensity to regional and distant metastasis. Only small retrospective series of patients were reported in the literature making the management of this disease unclear. There is no evidence that aggressive therapy offers better survival. Therefore, a better comprehension of the disease and the search of new modalities for the treatment is necessary.

\section{References}

1. Turner JH, Reh DD. Incidence and survival in patients with sinonasal cancer: a historical analysis of population-based data. Head Neck 2012;34(6):877-885. DOI: 10.1002/hed.21830.

2. Ejaz A, Wenig BM. Sinonasal undifferentiated carcinoma: clinical and pathologic features and a discussion on classification, cellular differentiation, and differential diagnosis. Adv Anato Pathol 2005;12(3):134-143. DOI: 10.1097/01.pap.0000163958.29032.56.

3. Rischin D, Porceddu S, Peters $L$, et al. Promising results with chemoradiation in patients with sinonasal undifferentiated carcinoma. Head Neck 2004;26(5):435-441. DOI: 10.1002/hed.10396. 
4. Tanzler ED, Morris CG, Orlando CA, et al. Management of sinonasal undifferentiated carcinoma. Head Neck 2008;30(5):595-599. DOI: 10.1002/hed.20748.

5. Frierson Jr HF, Mills SE, Fechner RE, et al. Sinonasal undifferentiated carcinoma. An aggressive neoplasm derived from schneiderian epithelium and distinct from olfactory neuroblastoma. Am J Surg Pathol 1986;10(11):771-779. DOI: 10.1097/00000478-19861100000004.

6. Musy PY, Reibel JF, Levine PA. Sinonasal undifferentiated carcinoma: the search for a better outcome. Laryngoscope 2002;112(8 Pt 1):1450-1455. DOI: 10.1097/00005537-200208000-00023.

7. Mendenhall WM, Mendenhall CM, Riggs Jr CE, et al. Sinonasal undifferentiated carcinoma. Am J Clin Oncol 2006;29(1):27-31. DOI: 10.1097/01.coc.0000189691.04140.02.

8. Kuo P, Manes RP, Schwam ZG, et al. Survival outcomes for combined modality therapy for sinonasal undifferentiated carcinoma. Otolaryngol Head Neck Surg 2016;156(1):132-136. DOI: 10.1177/0194599816670146.

9. Jeng $Y M$, Sung $M T$, Fang $C L$, et al. Sinonasal undifferentiated carcinoma and nasopharyngeal-type undifferentiated carcinoma: two clinically, biologically, and histopathologically distinct entities. Am J Surg Pathol 2002;26(3):371-376. DOI: 10.1097/00000478200203000-00012.

10. Xu CC, Dziegielewski PT, McGaw WT, et al. Sinonasal undifferentiated carcinoma (SNUC): the alberta experience and literature review. J Otolaryngol Head Neck Surg 2013;42(1):2. DOI: 10.1186/19160216-42-2.
11. Enepekides DJ. Sinonasal undifferentiated carcinoma: an update. Curr Opin Otolaryngol Head Neck Surg 2005;13(4):222-225. DOI: 10.1097/01.moo.0000172806.56382.eb.

12. Kim BS, Vongtama R, Juillard G. Sinonasal undifferentiated carcinoma: case series and literature review. Am J Otolaryngol 2004;25(3): 162-166. DOI: 10.1016/j.amjoto.2003.12.002.

13. Edwards PC, Hess SJ, Saini T. Sinonasal undifferentiated carcinoma of the maxillary sinus. J Can Dent Assoc 2006;72(2):163-167.

14. Branstetter BFt, Weissman JL. Role of MR and CT in the paranasal sinuses. Otolaryngol Clin North Am 2005;38(6):1279-1299. DOI: 10.1016/j.otc.2005.08.013.

15. Sievers KW, Greess H, Baum U, et al. Paranasal sinuses and nasopharynx CT and MRI. Euro J Radiol 2000;33(3):185-202. DOI: 10.1016/s0720-048x(99)00142-4.

16. Lund VJ, Howard DJ, Lloyd GA, et al. Magnetic resonance imaging of paranasal sinus tumors for craniofacial resection. Head Neck 1989;11(3):279-283. DOI: 10.1002/hed.2880110316.

17. Fouad Mourad W, Hauerstock D, Shourbaji RA, et al. Trimodality management of sinonasal undifferentiated carcinoma and review of the literature. Am J Clin Oncol 2013;36(6):584-588. DOI: 10.1097/ COC.0b013e31825eb3a5.

18. Reiersen DA, Pahilan ME, Devaiah AK. Meta-analysis of treatment outcomes for sinonasal undifferentiated carcinoma. Otolaryngol Head Neck Surg 2012;147(1):7-14. DOI: 10.1177/0194599812440932.

19. Righi PD, Francis F, Aron BS, et al. Sinonasal undifferentiated carcinoma: a 10-year experience. Am J Otolaryngol 1996;17(3): 167-171. DOI: 10.1016/s0196-0709(96)90055-1. 